\title{
A case of epiphora and recurrent basal cell carcinoma of the nasal tip and review of acquired nasolacrimal system obstruction
}

\author{
Wendy Lynne Parker MD PhD ${ }^{1,2}$, Marie-Lucie Lessard MD FRCSC FRCSC FACS ${ }^{2}$
}

\begin{abstract}
WL Parker, M-L Lessard. A case of epiphora and recurrent basal cell carcinoma of the nasal tip and review of acquired nasolacrimal system obstruction. Can J Plast Surg 2004;12(4):201-204.
\end{abstract}

A case of a 67-year-old man with recurrent basal cell carcinoma of the nasal tip and an incidental symptom of epiphora (volunteered by the patient) is presented. Epiphora is an abnormal overflow of tears that fail to drain into the inferior nasal meatus via the nasolacrimal system. Within the differential diagnosis of epiphora and nasolacrimal obstruction is neoplasm - primary, secondary or metastatic. On further investigation, including computed tomography imaging, he was subsequently found to have invasive disease extending along the left embryological cleavage plane superiorly to the medial canthal tendon. An excision attempt using Mohs technique by the dermatological surgeon was unsuccessful in adequately clearing the margins, and revealed a diagnosis of morphea-like basal cell cancer. This failure, taken together with the extent of disease identified by computed tomography scan, resulted in significant alteration of the operative approach. The patient underwent extensive tumour extirpation and nasal reconstruction using a forehead flap.

The present case alerts surgeons involved in the management of skin cancers to the importance of the anatomical relationship of the nasolacrimal apparatus to embryological soft tissue cleavage planes when dealing with recurrent and aggressive lesions. In addition, it serves as a reminder to inquire about the signs and symptoms associated with nasolacrimal obstruction. Moreover, when preparing for surgical excision of recurrent aggressive basal cell carcinoma, high-quality imaging is essential to tailor the operative plan.

Key Words: Basal cell carcinoma; Epiphora; Lacrimal duct; Nasolacrimal obstruction; Recurrent basal cell carcinoma

\section{Un cas d'épiphora et de carcinome basocellu- laire récurrent de la pointe du nez et une analyse de l'obstruction acquise du système lacrymonasal}

Le cas d'un homme de 67 ans souffrant d'un carcinome basocellulaire récurrent de la pointe du nez et d'un symptôme d'épiphora accessoire (souligné par le patient) est présenté. L'épiphora est un trop-plein anormal de larmes qui ne se draine pas dans le méat nasal inférieur par le système lacrymonasal. Le néoplasme (primaire, secondaire ou métastatique) fait partie du diagnostic différentiel d'épiphora et d'obstruction lacrymonasale. Après un examen plus approfondi, y compris une tomodensitométrie, on a découvert que le patient souffrait d'une maladie envahissante se prolongeant sur le plan de clivage embryologique gauche, au-dessus du tendon canthal médian. Le chirurgien dermatologique a tenté une excision au moyen de la technique de Mohs, laquelle n'a pas réussi à bien désobstruer les bords et a révélé un diagnostic de cancer basocellulaire morphéiforme. Cet échec, ajouté à l'étendue de la maladie repérée par tomodensitométrie, a entraîné une importante modification de la démarche opératoire. Le patient a subi une extirpation importante de la tumeur et une reconstruction nasale au moyen d'un lambeau du front. Ce cas révèle aux chirurgiens qui participent à la prise en charge des cancers cutanés toute l'importance de la relation anatomique entre l'appareil lacrymonasal et les plans de clivage embryologiques des tissus mous en cas de lésions récurrentes et agressives. De plus, il rappelle qu'il faut s'informer des signes et symptômes associés à l'obstruction lacrymonasale. De plus, au moment de se préparer à l'excision chirurgicale d'un carcinome basocellulaire agressif et récurrent, une imagerie de haute qualité est essentielle à la personnalisation de la planification opératoire.
$\mathrm{T}$ he interest of this case presentation, of a morphea-like basal cell carcinoma (BCC) of the nose, stems from the near-distant involvement of the lacrimal duct. Therefore, it is necessary to review the embryological anatomy of the nasolacrimal apparatus. The nasolacrimal draining system begins as an invagination of ectodermal cells along the cleft between the lateral nasal process and the maxillary process of the face. This fold extends into the mesenchyma, forming the naso-optic fissure, and detaches from the surface to form a solid cord of cells between the medial canthus and the nasal cavity during the sixth to 12 th week of gestation. A proliferation of cells also begins to form a rudimentary lacrimal sac at this time. The puncta become patent onto the eyelid margins just before the eyelids separate at the seventh month of gestation (1).

The lacrimal puncta separate the ciliated and nonciliated portions of the eyelid margin. The upper lid punctum lies slightly more medially than that of the lower lid. Normally they are tilted posteriorly, surrounded by a ring of elastoid dense connective tissue, and pushed inward by the tone of the orbicularis oculi muscle. The canaliculi average $0.5 \mathrm{~mm}$ to $2.0 \mathrm{~mm}$ in diameter and $10 \mathrm{~mm}$ to $12 \mathrm{~mm}$ in length, and join the puncta with the lacrimal sac. The lacrimal sac, the widest

${ }^{1}$ Plastic Surgery Resident, McGill University; and ${ }^{2}$ Division of Plastic and Reconstructive Surgery, Royal Victoria Hospital, McGill University, Montreal, Quebec

Correspondence: Dr Lucie Lessard, Division of Plastic Surgery, Montreal General Hospital, Livingston Hall Pavilion L9-317,

1650 Cedar Avenue, Montreal, Quebec H3G 1A4. Telephone 514-934-1934 ext 44341, fax 514-934-8207,

e-mail lucie.lessard@muhc.mcgill.ca 
portion of the draining system, is situated in the lacrimal fossa in the anterior portion of the medial orbital wall. The sac is $12 \mathrm{~mm}$ to $15 \mathrm{~mm}$ long, $3 \mathrm{~mm}$ to $5 \mathrm{~mm}$ of which sits above the medial canthal tendon, and is $4 \mathrm{~mm}$ to $8 \mathrm{~mm}$ in anteriorposterior diameter. This is loosely surrounded by a fascial sheath. The bony lacrimal fossa is formed at the fusion point of the embryonic maxillary and nasal processes and is commonly marked by a small sulcus or lacrimal tubercle. The $12 \mathrm{~mm}$ to $18 \mathrm{~mm}$ long nasolacrimal duct connects the inferior portion of the sac to the inferior nasal meatus. Its surrounding bony canal is formed by a groove in the maxilla, lacrimal bone and lacrimal process of the inferior nasal concha. It then opens under the inferior turbinate approximately $3 \mathrm{~cm}$ deep and posterior to the external nares in a horizontal plane (2).

The volume of tears necessary to moisten the globe of the eye is approximately $1 \mathrm{~mL} /$ day (3). Epiphora is the symptom associated with increased lacrimation or decreased tear drainage. Excess production of tears is rare compared with abnormalities in drainage, but may be stimulated by lid malposition, foreign bodies, irritants, eyelid margin disease or abnormalities of the trigeminal nerve. Deficiency in tear drainage, once eyelid laxity and local pathology have been excluded, equates to an obstruction, partial or complete, at some level of the nasolacrimal apparatus.

Depending on the etiology of obstruction, other signs and symptoms may be noted. With obstruction secondary to lacrimal sac neoplasms, $\mathrm{Ni}$ et al (4) state that not only is epiphora present in all patients for a period of months to years, but also one occasionally sees nasal obstruction with epistaxis, purulent discharge, blood regurgitation through the punctum, and, possibly, infraorbital nerve paresthesia. With more extensive disease, a palpable mass over the sac region and acute inflammation, often misdiagnosed as dacryocystitis, may be apparent. When the disease is extensive enough to create proptosis or decrease ocular motility, regional lymph node involvement is common. Swelling above the medial canthal tendon is also recognized by Nowinski (2) as suggestive of a neoplasm rather than an infectious etiology.

The recognition of these signs and symptoms is important for a successful oncological surgery in cases of morphea-like BCC. In their original article in 1975 (3), on review of BCC of the medial canthal area, Bostwick et al recognized that epiphora and purulent drainage simulating dacryocystitis suggest extension into the lacrimal system.

\section{Etiology}

As already apparent, these diverse clinical presentations all signify obstruction and involvement of the nasolacrimal system; however, they do not clarify the etiology or level of the obstruction. In 1986, Linberg and McCormick (5) biopsied nasolacrimal ducts in 16 patients presenting with obstruction, and diagnosed 14 of these with primary acquired nasolacrimal duct obstruction. They grouped the secondarily acquired obstructions into four categories: primary neoplasms, secondary neoplasms, inflammatory or infectious. In 1992, Zapala et al (6) reviewed 70 patients from 1974 to 1990 with lacrimal drainage obstruction. The cause of the obstruction was classified as trauma, postinflammatory stenosis, tumours of the eyelids and medial canthal region, or iatrogenic laceration, with incidences of $64.3 \%, 18.6 \%, 12.9 \%$ and $4.3 \%$, respectively. In 1992 to 1993, Bartley (7-9), in a three-part review of acquired lacrimal drainage obstruction, coined the mnemonic SALDO, for secondary acquired lacrimal drainage obstruction. In this extensive etiological classification, he divides SALDO into the following categories: infectious - bacterial, viral and fungal; inflammatory - endogenous and exogenous; neoplastic primary, secondary and metastatic; traumatic - iatrogenic and noniatrogenic; and mechanical - internal and external.

\section{Diagnosis and investigations}

Accurate diagnosis of a nasolacrimal duct obstruction is essential for appropriate treatment. To objectively diagnose epiphora, Schirmer's test can be performed. This entails anesthetizing the conjunctiva of the eye, then placing a $5 \mathrm{~mm} \times 30 \mathrm{~mm}$ Whatman filter paper (Whatman Inc, United Kingdom) into the conjunctival fornix for $5 \mathrm{~min}$ (10). To more definitively diagnose the duct obstruction, Jordan (10) describes a series of three simple tests. Dye disappearance and the Jones I and Jones II tests provide accurate diagnosis in over $95 \%$ of tearing patients if done sequentially. $\mathrm{Ni}$ et al (4) consider dacryocystography to be valuable because patency of probing the duct system does not rule out carcinoma. However, they recommend that biopsy in conjunction with dacryocystography is definitive. Zapala et al (6) cite $12.9 \%$ of 70 patients' lacrimal drainage obstructions are from tumours, but consider probing, irrigation and, possibly, dacryocystography to be adequate for establishing diagnosis and level of obstruction. Certainly, there is no agreed upon protocol for investigation of epiphora and nasolacrimal system obstruction in the literature beyond dye studies, probing and dacryocystography. Yet, the incidence of unsuspected neoplasm on biopsy of the nasolacrimal duct for obstruction is found to be $0 \%$ to $12.5 \%(5,11)$.

Here we present a case report of a 67-year-old man with recurrent nasal tip BCC and epiphora, and an argument for more extensive preoperative investigations when symptoms of nasolacrimal system obstruction accompany primary, recurrent or metastatic neoplastic disease.

\section{CASE PRESENTATION}

The patient was a 67-year-old male retired park superintendent, nonsmoker and nondrinker, with hypertension, coronary artery disease and type II diabetes mellitus. He had been treated five years previously at another institution for BCC of the left nasolabial area. Initially the lesion was excised and closed with a cheek advancement flap. The first recurrence came two years later and was again excised and the left cheek readvanced. The second recurrence was detected the following year at the nasal tip and treated by excision and full-thickness skin grafting. The patient did not receive postoperative radiotherapy. He was referred to the dermatology department at the McGill University Health Center with evidence of a fourth recurrence at the margin of the previous skin graft. Mohs excision was indicated and appropriately planned and the patient was referred to our plastic surgery clinic for reconstructive consultation. The patient clearly described the symptom of epiphora of the left eye. Nasal speculum exam revealed no findings, nor was there any evidence of inflammation or mass over the left nasolacrimal duct apparatus. However, because this represented the fourth recurrence for this patient and because of his associated incidental finding of epiphora, a computed tomography (CT) scan was performed (Figure 1). The CT revealed that the carcinoma was extending in a subcutaneous plane up to the left medial canthal tendon, involving the nasolacrimal duct, sac and bony fossa. 


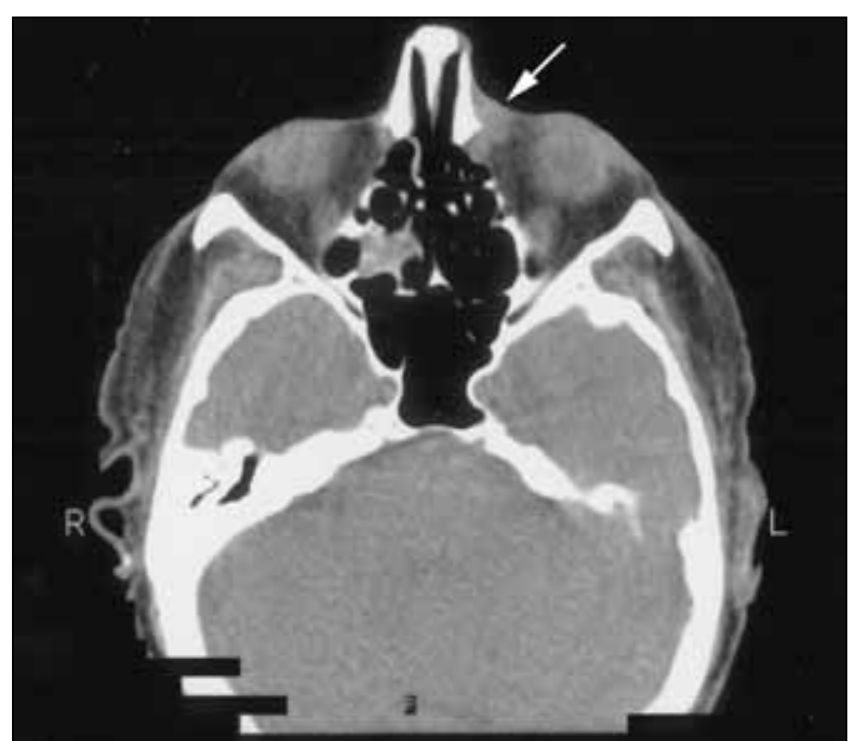

Figure 1) A coronal computed tomography revealed extensive soft tissue invasion by the left nasolabial basal cell carcinoma. The mass extended in a subcutaneous plane to the left medial canthal tendon, nasolacrimal duct, sac and bony fossa (white arrow)

The recurrence was initially believed to be isolated to the nasal tip. However, findings from the CT scan indicated that the lesion was extensive and would require aggressive resection and reconstruction. The Mohs surgery was undertaken by the dermatologist yet was unsuccessful in obtaining tumour-free margins in the medial canthal area, infraorbital rim and nasolacrimal duct. The patient was returned to the operating room for definitive excision of the tumour. Gross residual disease of approximately $1 \mathrm{~cm} \times 1.5 \mathrm{~cm}$ was noted, extending along the left nasolabial fold superiorly to the medial canthal area, along the infraorbital rim, and medially replacing the lacrimal sac and fossa. This neoplastic tissue was excised and all margins were sent for frozen section. Positive margins were found at the infraorbital rim and deep lacrimal fossa. These zones were re-excised to achieve negative margins (Figures 2A and 2B). A left medial canthopexy, a mucoperichondrial hinge flap from the right nasal septum for left nasal lining, a left cheek advancement flap and a contralateral forehead flap were used to reconstruct the tissue defects (Figures 2C and 2D). A left dacryocystorhinostomy was performed and stented with Crawford tubes through both upper and lower puncta. There were no postoperative complications and the patient was returned to the operating room three weeks later for division of the forehead flap (Figure 3). In the interim, the patient was referred to the radiation-oncology department for future radiation therapy. Histology was consistent with BCC but, uniquely, showed deep invasion with extensive perineural invasion but no squamous cell-like changes. The combined clinical picture and histology resulted in a final diagnosis of a morpheaform variant.

\section{DISCUSSION}

BCC, the most common carcinoma of Caucasians, arises from the basal cell layer of the skin or the external root sheath of a hair follicle (12). Eighty-six per cent of BCC occur on the face and scalp; $25.5 \%$ of these are found on the nose (13).
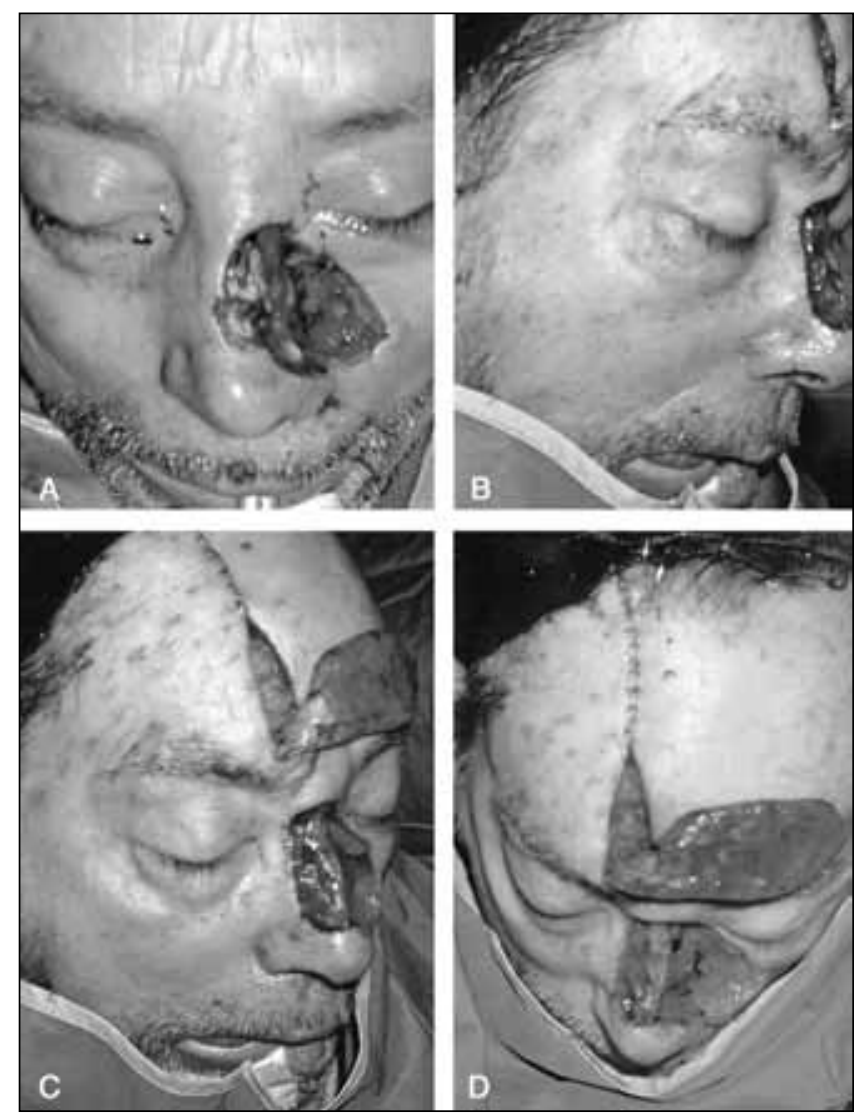

Figure 2) A and B Extensive dissection to achieve negative frozen margins resulted in a large operative defect seen in anteroposterior and lateral projections. C and D Closure was achieved with a left medial canthopexy, a mucoperichondrial hinge flap from the right nasal septum, left cheek advancement and a contralateral forehead flap. A dacryocystorhinostomy was required. The raised forehead flap is evident with closure of the donor site

Although the rate of metastasis for BCC is less than 0.1\% (13), the five-year recurrence rate is $0 \%$ to $9 \%$, and $47 \%$ of these recur again (12). Thus, the importance of early complete excision is obvious. The cure rate with surgery is greater than $90 \%$ and may rise as high as $99 \%$ with Mohs surgery (13). Bostwick et al (3) reviewed BCC of the medial canthal area in 1975. They acknowledged that epiphora suggested extension of the disease to the lacrimal system and any portion involved must be excised with negative frozen margins. They recommended a partial maxillectomy, resection of the entire inferior turbinate if significant involvement with disease, and possibly the tarsal plate and medial canthal tendon with immediate reconstruction (3). Zapala et al (6) recommended that if the etiology of nasolacrimal system obstruction is oncological, then radical excision is the main aim of treatment.

The plastic surgery community is vigilant about skin cancer; however, here we have presented a case of a recurrent nasal tip BCC with a more complex clinical picture than originally anticipated. A fourth recurrence at the margin of a fullthickness skin graft on the nasal tip, on further CT imaging, was found to be invasive subcutaneous disease extending along the left nasomaxillary embryological plane to the left medial canthal tendon and infraorbital rim, replacing the lacrimal sac and filling the lacrimal fossa. The BCC involvement of the 

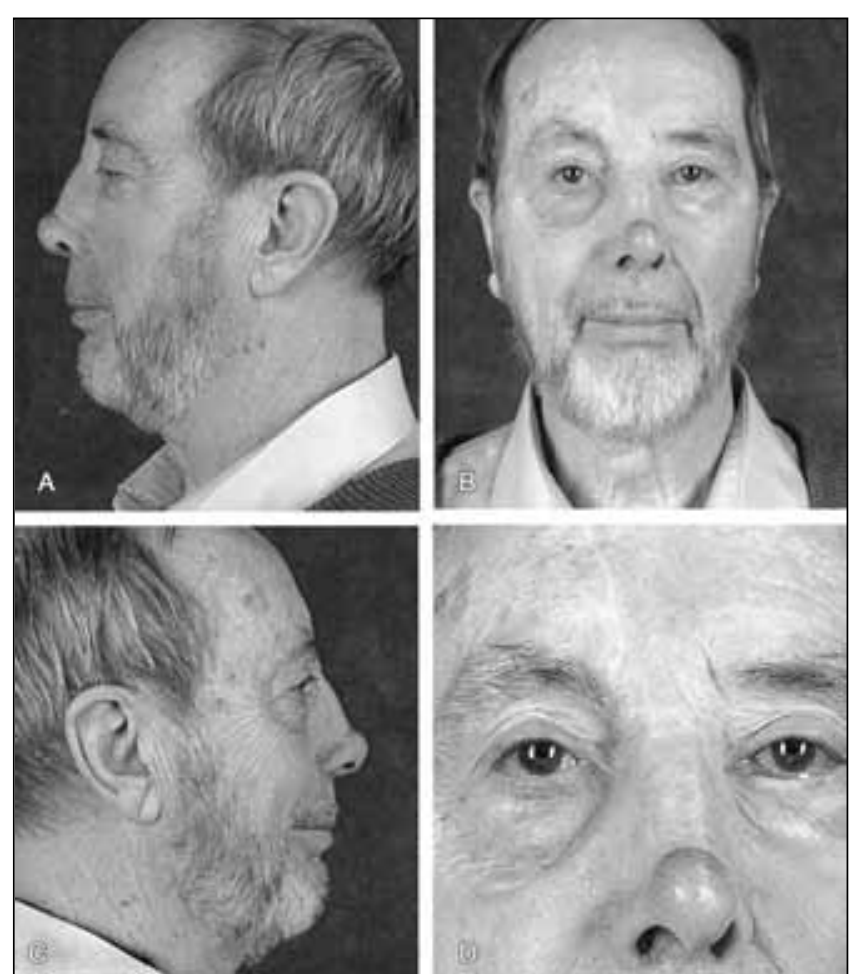

Figure 3) A reasonable reconstructive result and a functional left nasolacrimal duct are achieved

nasolacrimal system explains our patient's symptom of epiphora from nasolacrimal obstruction. These radiological findings resulted in a more extensive tumour extirpation and nasal reconstruction using a forehead flap. This case alerts surgeons involved in the management of skin cancers to the importance of the anatomical relationship of the nasolacrimal apparatus to embryological soft tissue cleavage plains when dealing with recurrent and aggressive lesions. In addition, it reminds us to inquire about the signs and symptoms associated with nasolacrimal obstruction. Moreover, when preparing for surgical excision of recurrent aggressive BCC, high-quality imaging is essential to tailor the operative plan depending upon the lesion extent. For extensive lesions, this may involve aggressive wide local resection or possible orbital exenteration requiring elaborate reconstruction.

\section{REFERENCES}

1. Duke-Elder S, Cook C. Normal and abnormal development: Part I. Embryology. In: Duke-Elder S, ed. System of Ophthalmology, Volume 3. St Louis: CV Mosby, 1963.

2. Nowinski TS. Lacrimal surgery. In: Bosniak S, ed. Principles and Practice of Ophthalmic Plastic and Reconstructive Surgery, Volume 2. Philadelphia: WB Saunders, 1996:731-47.

3. Bostwick J 3rd, Vasconez LO, Jurkiewicz MJ. Basal cell carcinoma of the medial canthal area. Plast Reconstr Surg 1975;55:667-76.

4. Ni C, D'Amico DJ, Fan CQ, Kuo PK. Tumors of the lacrimal sac: A clinicopathological analysis of 82 cases. Int Ophthalmol Clin 1982;22:121-40.

5. Linberg JV, McCormick SA. Primary acquired nasolacrimal duct obstruction. A clinicopathological report and biopsy technique. Ophthalmology 1986;93:1055-63.

6. Zapala J, Bartkowski AM, Bartkowski SB. Lacrimal drainage system obstruction: Management and results obtained in 70 patients. J Craniomaxillofac Surg 1992;20:178-83.

7. Bartley GB. Acquired lacrimal drainage obstruction: An etiologic classification system, case reports, and a review of the literature. Part 1. Ophthal Plast Reconstr Surg 1992;8:237-42.

8. Bartley GB. Acquired lacrimal drainage obstruction: An etiologic classification system, case reports, and review of the literature. Part 2. Ophthal Plast Reconstr Surg 1992;8:243-9.

9. Bartley GB. Acquired lacrimal drainage obstruction: An etiologic classification system, case reports, and review of the literature. Part 3 Ophthal Plast Reconstr Surg 1993;9:11-26.

10. Jordan DR. Evaluation of the tearing patient. In: Bosniak S, ed. Principles and Practice of Ophthalmic Plastic and Reconstructive Surgery, Vol 2. Philadelphia: WB Saunders, 1996:748-61.

11. Mauriello JA Jr, Palydowycz S, DeLuca J. Clinicopathologic study of lacrimal sac nasal mucosa in 44 patients with complete acquired nasolacrimal duct obstruction. Ophthal Plast Reconstr Surg 1992;8:13-21.

12. Stal S, Spira M. Basal and squamous cell carcinoma of the skin. In: Aston SJ, Beasley RW, Thorne CHM, eds. Grabb and Smith's Plastic Surgery, 5th edn. Philadelphia: Lippincott-Raven, 1997:107-20.

13. Netscher DT, Maher A, Spira M. Premalignant skin tumors, basal cell carcinoma, and squamous cell carcinoma. In: Cohen M, ed. Mastery of Plastic and Reconstructive Surgery. Boston: Little, Brown and Co, 1994:309-32. 